\title{
Chapter 15 \\ Knowledge, Skill, and Wisdom: \\ Reflections on Integrating the Social \\ Sciences and Engineering
}

\author{
W. Bernard Carlson
}

Throughout the world, individuals and nations now depend on complex technological systems to provide food, shelter, energy, and information, and these systems are largely the product of engineering expertise. In building these systems, engineers have developed a deep knowledge of the forces of nature, and they sustain and disseminate this knowledge by organizing it into specialties. Yet as our dependency on engineering increases, fewer and fewer laymen - or even engineers themselves-have a grasp on the overall nature of engineering knowledge. Concentrating on their specialties, engineers have not been called upon to articulate the basic intellectual assumptions of their discipline, to describe the social and cognitive processes by which they create and apply new knowledge, or to explain to the public the role of engineering in society. Caught between dependence and specialization, lay people find themselves increasingly frustrated and suspicious of engineers and technology; while they find more computers and machines in their lives, lay people feel that they know less and less about technology. At the same time, engineers continue to use specialization to organize their knowledge, but they are often troubled that their expertise does not translate into the social, economic, and political power needed to bring about technological progress.

\subsection{Knowledge, Skill, and Wisdom}

In order to address the tensions surrounding dependency and specialization, my colleagues and I in the School of Engineering and Applied Science at the University of Virginia (UVA) believe that engineers need to become reflective practitioners

\footnotetext{
W. B. Carlson $(\bowtie)$

Engineering and Society Department, University of Virginia,

Charlottesville, VA, USA

e-mail: wc4p@virginia.edu

(C) The Author(s) 2018

E. Subrahmanian et al. (eds.), Engineering a Better Future,

https://doi.org/10.1007/978-3-319-91134-2_15
} 
who understand both the power and the limits of their professional expertise (Schon 1984). In our view, reflective practitioners in engineering are individuals capable of thinking about the nature of engineering knowledge. This does not mean that engineers need to formulate a highly complex epistemology. Instead, one of my colleagues, Gorman (1998), has found it useful to think about engineering in three simple categories: knowledge, skill, and wisdom.

In Gorman's framework, knowledge refers to the "facts" - the information-that engineers use in solving problems. Knowledge may include equations, theories, and models as well as specific devices and circuits. Yet it is not enough to possess engineering facts; one must also know how to use them. Gorman uses the term skill for knowing how to employ information. For example, in most engineering schools, students are taught how to represent complex natural phenomena in terms of mathematical equations, how to solve those equations, and to use the solutions to predict the future state of the phenomena. Equations are the knowledge, while skill is knowing how to apply the equation and evaluate the results. Of course, to become effective engineers, students need to acquire not just mathematical virtuosity but other skills such as design protocols, laboratory procedures, sketching, writing, and speaking (and I'll say more about this later when I talk about representation).

But beyond information and skill, engineering students need wisdom. By wisdom, Gorman means that students should learn when and why it is appropriate to apply their skills. Students need to know when representing a problem mathematically will yield useful information and a valid prediction. They need to be sensitive to how important aspects of natural and social phenomena cannot be measured or quantified and hence not included in a mathematical model. Students need to have the wisdom to ask what implicit assumptions may be built into a theory, model, or software package, assumptions that could lead to erroneous and even disastrous results. And they should be able to think about the larger social and cultural goals to which they are applying their expertise. As Paul Goodman once observed, "[T]echnology ... aims at prudent goods for the commonweal .... As a moral philosopher, a technician [or engineer] should be able to criticize the programs given him [or her] to implement" (Martin and Schinzinger 1989, 1). Wisdom is being able to discuss which goods are prudent, what constitutes the common wealth of a society, and which engineering practices will contribute to the good society.

Wisdom may seem like an overblown and presumptuous term, but I think it is exactly the right word for what we are talking about here. Wisdom captures the mysterious quality which separates the expert from the novice, the engineer from the technician-judgment. We depend on all professionals to exercise judgmentto be able to make decisions about what to do and to acknowledge that decisions have consequences. The word wisdom elevates judgment beyond mere skill, reminding us that those entrusted with knowledge and skill must exercise their power thoughtfully, carefully, and ethically.

My purpose in introducing this three-part model of engineering knowledge is to make a simple point: we engineering educators spend far too much time cramming 
knowledge and skills into the heads of our students. In my opinion, much of what passes for reform engineering education today in America simply concerns increasing the amount of knowledge and skills that will be imparted to our students. We naively assume that the students will somehow acquire wisdom on the job or perhaps through divine intervention. Unfortunately, students tend to value only what we teach them. If we only teach our students knowledge and skills and neglect wisdom, then many of them will not appreciate the importance of wisdom. If we want engineering students to become reflective practitioners-capable of producing prudent goods for the commonweal-then we need to devote a portion of the undergraduate curriculum to cultivating wisdom.

\subsection{An Overview of UVA's Program in Science, Technology, and Society}

So, how then might we go about cultivating wisdom in engineering education? At UVA, we help engineering students to become reflective practitioners by teaching a series of required undergraduate courses which combine instruction in writing and speaking with a discussion of the nature of knowledge and the interaction of technology and society. Let me turn now to providing a brief overview of the University of Virginia and the Program in Science, Technology, and Society (STS). Following this overview, I will then suggest several of the key concepts from the humanities and social sciences which we strive to convey to our undergraduate engineering students at Virginia.

A bit of institutional context is perhaps useful here. By American standards, the University of Virginia (UVA) is a medium-sized state university with a total enrollment of 24,000. The School of Engineering and Applied Science is small by American standards, enrolling 3700 students in its undergraduate (2800) and graduate (900) programs. The engineering faculty totals 160 tenure-track faculty, and the STS program has 7 tenure-track and 7 teaching faculty. STS has long been a part of UVA Engineering and was founded in 1932 as Engineering English. At that time the university was highly decentralized, and engineering students could only take courses in the School of Engineering; they could not enroll in courses in the College of Arts and Sciences. Consequently, when the engineering faculty decided that their students should have instruction in writing, speaking, and the humanities, the logical step was to create a program inside the Engineering School. In the 1960s, the Division began offering courses in literature, history, aesthetics, and photography, and its name was changed to the Humanities Division. In the 1990s, as the Division acquired a stronger research program in STS and the history of technology, so it was renamed the Department of STS. In 2012, the STS program joined with Applied Mathematics and technology entrepreneurship to create the Department of Engineering and Society. Today, the STS program has a diverse 
faculty, with specialists in literature, history, anthropology, psychology, and sociology.

Over the years, the STS Program has pursued two basic missions: first, to teach engineering students to write and speak effectively; and second, to inspire students to think in rich and sophisticated ways about the links between technology and culture. The Division achieves these goals by offering four courses which are required for all undergraduate engineers. In the first semester, students take STS 1500 which covers the fundamentals of writing and speaking for professionals. The course also introduces them to engineering as a profession and a discipline. In STS 1500 , we argue that writing and speaking are as important as mathematical skills for the engineers, and we suggest how one must need to use these skills flexibly and ethically.

During their second or third year, the students take a 2000- or 3000-level course on technology and society. The Program offers a range of these courses and they reflect the research interests of the faculty. We offer several courses on the history of technology, but in addition we also teach courses on utopian thinking, literature and technology, social theory of technology, creativity, and entrepreneurship.

While the topics vary, the thrust of these courses is to help the students to think about the ways in which people shape technology to reflect social and cultural goals. At the same time, we use these courses to continue to sharpen the students' communication skills, and we require the students to write several extended essays, give speeches, and analyze key texts from the humanities and social sciences.

In their fourth year, the students take a two-course sequence, STS 4500-4600, in which they write their engineering theses. The undergraduate thesis is an independent engineering project that demands creativity, long-term planning, and professional responsibility. Each student selects a topic, pursues research in the laboratory, library, or field, and then prepares a portfolio consisting of a technical report and an STS analysis of the research undertaken. Although the students often investigate highly technical topics, UVA Engineering prides itself on turning out engineers who can communicate with a variety of audiences, and this goal is achieved by having STS professors serve as the principal thesis advisers. Consequently, much of the 4500-4600 sequence is devoted to helping students design their projects and to honing their writing skills, but a portion is also devoted to discussing engineering ethics. Overall, the 4500-4600 sequence helps our students move from being passive consumers of engineering knowledge to being active producers of knowledge who can solve problems and create new designs.

Much of our energy in the STS Program is devoted to undergraduate engineering education. However, this does not mean that my colleagues and I do not have active research programs. Indeed, our undergraduate teaching has stimulated many of us to step up our research and writing efforts. Because we are deeply involved in the education of engineers, we often see how concepts and theories from STS do not fully explain the processes by which engineering knowledge is 
generated and transmitted. By being at the point of knowledge production (to use Bruno Latour's phrase), my colleagues and I often see issues and puzzles that stimulate our ongoing study of technology.

Moreover, the engineering students often pose questions about technology and society which cannot be answered by simply referring them to some existing book or article; all too often, the STS literature is written for a highly specialized audience of scholars in the humanities and social sciences and the literature is not accessible to professional engineers. And finally, by being an interdisciplinary group in a professional school, my colleagues and I stimulate each other to think outside the standard disciplinary boundaries and to frame research problems in new ways. As a result of all of this stimulation, my colleagues and I have a variety of ongoing research projects which have been supported by grants from the National Science Foundation, the National Endowment for the Humanities, the Social Science Research Council, and the Sloan Foundation.

\subsection{Key Concepts}

With this overview in place, let me turn now to the ideas we try to impart to our students in this curriculum. I want to explain these themes because, in many ways, it may be the ideas, not the curriculum, that can be transferred from one institution to another. As an aid to learning, I have condensed these themes into aphorisms, but of course, these slogans do not fully capture all the nuances of what we try to convey to the students.

(1) To represent is to know. This slogan embodies a fundamental assumption about how humans learn about the material world and gain mastery over it. As the cognitive scientist, Donald Norman (1993), argued, humans solve problems by creating different kinds of representations. By picturing a problem using different images, words, symbols, or numbers, we are able to isolate key factors, identify patterns, and come up with solutions. Frequently, people use a range of different representational techniques - taking notes, making sketches, writing equations - to acquire, and organize information about the world. In engineering education, we pride ourselves on teaching students a host of representational techniques: complex mathematics, powerful computer models, precise ways of drawing, and rigorous ways of writing and speaking. We teach these techniques so that students can analyze, predict, and eventually control the forces of nature. Yet, while engineers intuitively know that the power of their profession is grounded in their ability to represent the natural world, we educators frequently fail to convey this essential lesson to our students (Carlson 2003).

Consequently, in our STS courses, we strive not only to improve how our students represent technology through writing and speaking but we call their attention to the central role that representations play in technological problem-solving. We argue again and again with students that if you cannot describe a problem (i.e., represent it) then you will be hard pressed to solve it. As 
the novelist Robert Penn Warren used to say, "Clear writing is straight thinking." In making this argument, we are making a radical claim about engineering, emphasizing that communications is not ancillary to engineering but rather at the heart of engineering.

In my own first-year communications course, I developed the theme of knowing and representing by having the students build a pendulum clock and then undertaking a series of written and oral assignments related to the clock. In order to appreciate how engineers use words and images to think, I have them revise the instructions, prepare an illustrated technical description, write a patent for an improvement on the clock, and prepare a manufacturing and marketing proposal (Carlson and Peterson 1996). In doing so, I was trying not only to improve the students' communications skills but also introduce a way of thinking about engineering. In particular, I suggested that they view their undergraduate education as a process by which they will master several different modes of representationmathematics, computer models, visual images, and words-and that the challenge is learning how best to apply these different modes to mastering natural and social phenomena. My students reported that this is often the one "big idea" they learned in their first year of engineering, and that it helped them to make sense of the overall education process.

The next two aphorisms embody what we try to teach the students about the interaction of technology and society.

(2) No widget advances without social allies; hence all engineers are sociologists. In this slogan, "widget" refers to any technological artifact, device or system, and I am revealing that much of what we teach reflects the actor-network approach in STS today. As Law and Callon (1992) argued, the successful introduction of a new widget depends on how well engineers are able to convince other social groups to produce and use the new widget. To use a familiar example from the history of technology, when Thomas Edison developed his incandescent lighting system in the late nineteenth century, he not only had to invent a new light bulb but he also had to convince capitalists to lend him money to finance his research, persuade the Patent Office to grant him patents for his inventions, secure permission from the government of New York City to lay cables under the streets, and convince consumers that his incandescent lighting was preferable to gas lighting (Hughes 1983; Bazerman 2002). In developing this and other examples with our engineering students, we strive to make the point that the development of the technology (i.e., the incandescent lamp) was not enough to create an electrical revolution; Edison had to be willing to negotiate and enroll a variety of groups into his socio-technical network. To succeed with these processes of negotiation and enrollment, Edison had to understand the structure of his society and the values of different groups. In this sense, Edison was a sociologist, and for the same reason, we argue that our students need to understand the structure and values of contemporary society. If UVA students wish to make sure that the widgets they design are put into widespread use, then they need to know something about the processes by which social groups appropriate technology. 
As you might expect, we cover how engineers and society negotiate new technology in our 2000- and 3000-level courses. Likewise, it should be readily apparent how this theme is tied to our communications mission-engineers can only recruit various groups by effectively communicating with them. To enroll groups in their networks, engineers must be able to describe technology clearly for nontechnical audiences and link the technology to the values of the target groups.

But even more than this, we use the undergraduate thesis as a hands-on exercise in building a socio-technical network. For instance, when I teach STS 4500, I introduce Law's (1987) notion of heterogeneous engineering, emphasizing that the success of a technological project depends on how well the engineer is able to hold together a series of technical and nontechnical elements. I then have the students identify the range of heterogeneous elements they need to bring together in their thesis project. I ask them to identify the equipment they will need, the people they will enroll (an engineering professor as technical adviser, support technicians, graduate students, and me), and the information and ideas (found in the engineering literature) which will justify and bolster their project.

In their project proposals, the students have to argue they can create this network and use it to accomplish their goal (i.e., getting new laboratory results or designing a new widget). In framing their thesis as a networking-building effort, I find that the students not only write better theses but they also begin to acquire the organizational skills they need to be effective leaders and managers.

(3) A society gets the technology it wishes for. This slogan is a modification of the old adage "A society gets the politics it deserves." This aphorism is an important supplement and corrective to the previous slogan. In the course of negotiating with social groups, it would be easy for students to come away with a sense that the negotiations related to technology turn on explicit, utilitarian values and issues. To return to the electric lighting example, all parties might agree with Edison that if his incandescent lighting system allowed for more illumination at cheaper prices, then everyone in society benefited - more street lights made the city safer, the middle class could enjoy lighting in their homes and businesses, workers got jobs in power plants and electrical equipment factories, while Edison and the capitalists earned a return on their investment.

But on another level, the negotiations often involve implicit cultural valuesthings for which a society wishes. Electric lighting "took off" in America in the late nineteenth century because it was perceived as being clean and modern, electrical utilities were seen as not being as corrupt as gas companies, and electrical systems provided a way of unifying communities, cities, and regions that might otherwise splinter along political and economic cleavages (Nye 1990). In our courses, we help students to appreciate how individuals such as Edison sometimes see and integrate these values into their socio-technical networks. At the same time, we remind students that often historical actors do not anticipate how their technological inventions will be linked to cultural values, and how these unexpected linkages often shift a technology away from its explicit utilitarian "bottom line". To explore the wishes that different societies have for technology, we often turn to literature, and our students read novels such as Frankenstein. 
The final slogan summarizes our view on the role of ethics in engineering: (4) Engineers cannot just throw technology over the wall. Consumers may choose to use technology in unexpected ways, and hence engineers need to exercise moral imagination. The first part of this aphorism reflects the danger and conceit of specialization in engineering. It is all too easy for our engineering students to say, "I'll do my bit-design my widget, but it is someone else's problem to figure out how it will be used." The obvious problem is that this attitude leads engineers to design technological artifacts that are not only difficult to use but in fact can have serious unintended consequences (Tenner 1996).

My colleagues and I believe that the best way to overcome this problem is to help students to develop their moral imaginations. According to Werhane (1996), a professor of business ethics at UVA, moral imagination refers to the ability of professionals to imagine a variety of outcomes for their decisions. Werhane emphasizes that if one is not able to imagine different scenarios, then one cannot assess the risk or apply a framework for moral reasoning (such utilitarianism, Kantian duty ethics, Lockean Right Ethics, or Aristotelian virtue ethics). Many of us have found that the most effective way to cultivate moral imagination is to teach cases similar to those used in business schools; these cases provide students with detailed background information and then challenge them to frame an ethically appropriate action. Working with a team of graduate students, Gorman et al. (1999) developed a series of cases which examine the ethical issues surrounding the design of environmentally sensitive products. Used in our STS 4500-4600 sequence, we find that these cases help students to clarify their views about the environment and practice applying different ethical theories to real-world situations.

In teaching Gorman's cases as well as other cases from business schools, another colleague, Rosanne Welker, and I (2001) have found that we can expand the moral imagination of students by getting them to consider how technologies can have four kinds of consequences: there can be good and bad consequences and there are intentional and unintentional consequences. In everyday life, engineers earn their keep by maximizing the positive intended consequences of a technological system while minimizing the negative intended consequences. If a technological system has unintended positive consequences, then these are seen by society as a bonus, and the engineers are treated quite suitably as heroes or geniuses. However, this leaves a fourth class of consequences, the unintended negative, with which no engineer wants to deal. Welker and I, however, argue that the ultimate challenge for an engineer is to have the character and courage necessary to imagine the unintended, negative consequences of his or her design. Moreover, we discuss with the students how different groups of technologists may develop collective design practices which minimize the likelihood that a particular artifact will fall into the negative, unintended design category and hence fail catastrophically. At the 
moment, our discussions often turn to traditional wooden shipbuilding, in which general principles permitted a certain amount of variation and innovation but at the same time generally ensured that most boats were safe from structural failure (Chapelle 1935).

Likewise, we debate with our students how centralized, hierarchically structured systems (for computing and telecommunications) have to be carefully designed so as not to have serious negative unintended consequences and crash catastrophically. To return to the beginning, the wisdom we would like our engineering students to have is to possess a moral imagination.

\subsection{Neither Preach nor Apologize}

These four aphorisms represent much of what we think and teach every day in the STS program at UVA. We believe that if we can convey these "big ideas" to the engineering students, then we are succeeding in integrating the humanities and social sciences into engineering education. These ideas, we hope, will permit our students to become reflective practitioners who will be capable of thinking about and directing technology toward the goals of the next generation. If we do our job well, then we are not just "humanizing" the engineers; indeed, we are creating a new breed of engineer.

But while my colleagues and I have lofty goals for our approach to teaching engineering students, we are nonetheless sensitive to the importance of not being arrogant. Over the years we have learned to try not to preach to the engineering students, taking the view that somehow we humanists have a broader and morally superior view of life. As tempting as it is to see the classroom as the opportunity to win converts for the First Church of Actor-Network Theory, we instead see our task as drawing on ideas from the STS literature and the history of technology in order to frame questions which help the students to think about their future role in society.

At the same time, my colleagues and I struggle not to be apologists for the status quo in engineering. All too frequently, people think that we should just teach the history of technology to undergraduates in order to demonstrate how great white men did great things with great machines and that this sort of history proves that we live in the best of all possible technological worlds. No, our task as humanists and social scientists who teach in an engineering school is not to confirm that the status quo. Rather our tasks are to prepare students who can imagine a better world and to provide them with the skills and wisdom that will permit them to create it. 


\section{References}

Bazerman, C. (2002). The languages of Edison's light: rhetorical agency in the material production of technology. Cambridge: MIT Press.

Carlson, W. B. (2003). Toward a Philosophy of Engineering: The Fundamental Role of Representation. In Proceedings of the american society for engineering education, CD-ROM.

Carlson, W. B., Peterson, K. (1996). Making clocks: a first-year course integrating professional communications with an introduction to engineering. In ASEE Proceedings, CD-ROM.

Carlson, W. B., Welker, R. (2001). The whammy line as tool for fostering moral imagination. In Proceedings of the american society for engineering education, CD-ROM.

Chapelle, H. I. (1935). The history of American sailing ships. New York: W. W. Norton.

Gorman, M. E. 1998. Transforming nature: ethics, invention, and discovery. Boston: Kluwer Academic Press.

Gorman, M. E., Mehalik, M., Werhane, P. (1999). Ethical and environmental challenges to engineering. Prentice-Hall.

Hughes, T. P. (1983). Networks of power: electrification in western society, 1880-1930. Baltimore: Johns Hopkins University Press.

Law, J. (1987). Technology and heterogeneous engineering: the case of portuguese expansion. In W. E. Bijker, T. P. Hughes, T. J. Pinch (Eds.), The social construction of technological systems (pp. 111-134). Cambridge: MIT Press.

Law, J., Callon, M. (1992). The life and death of an aircraft: a network analysis of technical change. In W. E. Bijker and J. Law (Eds.), Shaping technology/building society: studies in sociotechnical change (pp. 21-52). Cambridge: MIT Press.

Martin, M. W., Schinzinger, R. (1989). Ethics in engineering (2nd edn). New York: McGraw-Hill.

Norman, D. (1993). Things that make us smart: defending human attributes in the age of the machine. Reading, Mass.: Addison-Wesley.

Nye, D. E. (1990). Electrifying America: social meanings of a new technology, 1880-1940. Cambridge: MIT Press.

Schon, D. A. (1984). The reflective practitioner: how professionals think in action. New York: Basic Books.

Tenner, E. (1996). Why things bite back : technology and the revenge of unintended consequences. New York: Knopf.

Werhane, P. H. (1996). A Note on Moral Imagination. Case No. UVA-E-0114, Darden Graduate School of Business Adminstration, University of Virginia.

Open Access This chapter is licensed under the terms of the Creative Commons Attribution 4.0 International License (http://creativecommons.org/licenses/by/4.0/), which permits use, sharing, adaptation, distribution and reproduction in any medium or format, as long as you give appropriate credit to the original author(s) and the source, provide a link to the Creative Commons license and indicate if changes were made.

The images or other third party material in this chapter are included in the chapter's Creative Commons license, unless indicated otherwise in a credit line to the material. If material is not included in the chapter's Creative Commons license and your intended use is not permitted by statutory regulation or exceeds the permitted use, you will need to obtain permission directly from the copyright holder. 